\title{
MORPHOLOGICAL ANALYSIS FOR A GERMAN TEXT-'TO-SPEECH SYSTEM
}

\author{
Amanda Pounder, Markus Kommenda \\ Ingtitut für Nachrichtentechnik und Hochfrequenztechnik \\ Technische Universität Wien \\ Gusshausstrasse 25, A-1040 Wien, Austria
}

\section{ABSTRACT}

A central problem in speech synthesis with unrestricted vocabulary is the automatic derivation of correct pronunciation from the graphemic form of a text. The software module GRAPHON was developed to perform this conversion for German and is currently being extended by a morphological analysis component. This analysis is based on a morph lexicon and a set of rules and structural descriptions for German word-forms. It provides each text input item with an individual characterization auch that the phonological, syntactic, and prosodic components may operate upon it. This systematic approach thes serves to minimize the number of wrong transcriptions and at the same time lays the foundation for the generation of strese and intonation patterns, yieldins more intelligible, natural-sounding, and generally acceptable synthetic speech.

\section{INTRODUCTION}

Many applications of computer speech require unrestricted vocabulary. In particular, voice output units of this kind permit the linkage of the common telephone network to a central computer, thus enabling access for a large public. "Karlchen", the Frankfurt talking railway timetable, and other automatic information services are based on this principle.

If a written text serves as input to a speech synthesis system with unrestricted vocabulary (fext-tospeech synthesis), the derivation of a correct and natural-sounding pronunciation and intonation must, be provided for. The software module GRAPHON (GRAPHeme-PHONeme-convergion) has been developed to convert any given German text into its phonetic transcription (I.P.A.), enriched by some prosodic markers.
The text-to-speech system is being implemented on an HP 9816 workstation system with a $68000 \mathrm{CPU}$ and 768 kbyte of RAM. At present a SSI 263 phone eynthesizer serves as acoustical output unit; a simplified articulatory model used to control a refined digital vocal tract synthesizer is under development. The coftware is written in PASCAL and operation of the whole system in expected to be almost real-time. (For further implementational details of. [1].)

While text-to-speech systems for the English language are fairly advanced, there is much room for development, for German apeaking systems. It is possible only to a limited extent to profit from work in the field of English. Obviously, German pronunciation rules differ from those of other languages; however, the mere replacement of a given grapheme-to-phoneme conversion rule by another is inadequate to meet the demands of the very different principles on which two writing-systems are founded. This also applies to the structural levels of morphology and syntax.

\section{MOTIVATION FOR A MORPHOL,OGTCAL COMPONENT}

The application of an English pronunciation rule is lexically determined, that is to any, is restricted to a generally arbitrary subset of the lexicon (compare, for example, the values of 〈ea〉 in the sets 1 bread, head, thread...' and I knead, bead, heat... ) ). It is for this reason that many English-based systems include very extensive dictionarieg, for example the pioneering work of Allen [2] with a 12000 morpheme lexicon. On the other hand, German rules have in general a much wider scope of application, which has led researchers working in the field of German to consider large lexical inventories unnecessary. The inventories in e.g. SAMT [3] or SPIRAUS-VS [4] are thus restricted to Punction worda needed for the syntactic analysis (prepositions, pronouns, articles, etc.) Similarly, our earliest efforts in this area were based 
on a small lextcon and an extensive rule catalogue; however, numerous incorrect transcriptions at morphological boundaries and the frequent recurrence to ad-hoc rules (cf. [1]) made the lack of some sort of morphological indicator apparent.

However more closely German spelling may reflect pronunciation than is the case in English, difficulties arise in producing a correct pronunciation automatically if knowledge arailable to the human speaker, such as the internal structure of a given word or its native as opposed to foreign origin, is not made use of. The following examples should ouffice to demonstrate the relationship between morphology and the values of the written symbols:

- One fundumental rule is that vocalic quantity is determined by the number of following consonante: the firgt rule given in the DUDEN Aussprachewörterbuch [5] gtates that $\langle a\rangle$ is to be pronounced /a:/ when followed by only one consonant grapheme before the stem boundary, so that the inflectional form rast of the verb rasen ("rush") becomes /ra:st/, whereas the simplex noun Rast ("rest") becomes /rast/.

- Consonant or vowel groups may be aagigned digraph or trigraph value only when they appear within morphological boundaries; compare for example the different values of 〈sch〉 in löschen /S/ ("extinguish") und Högchen /aç/ (dim. of "pants"), or of (ei〉 in Geier /ai/ ("vulture") and geirrt /als/ ("erred").

- The first stem syllable in Gorman (native gtock) receives the primary word stress, a rule which implies this stem's being identifiable; compare geben /'ge:bn/ ("give") and Gebein /ga'bain/ ("bones").

These phenomena play a role in the domain of derivation and inflection, which has been dealt with in several systems, e.g. SYNTEX [6] or REDE [7]; these do contain lista of common prefixes and suffixes to permit affix-stripping, although they are predominantly rule-based. The same problems are found in the field of composition; their import it heightened by the very great frequency of this process in the German language. Still, Rühl [6] proposes a decomposition algorithm which relies on distributional criteria and on lists of consonant clusters in initial and final position (based on Kästner [8]). Other authors too prefer to minimize the lexical component: "The attempt to incorporate this problem into a mainly rule-based system seemed to us to require a rather great and thus undesired step towarda a kind of dictionary approach" ([9], p.226).

It is however certainly possible to make a case for a morphological analysis containing a morph-lexicon of some depth. The conversion program presented here makes extengive uge of such an analysis componont (see fig. 1) and thus in our opinion profits from the following advantages:

- inflection, derivation, and composition can be treated simultaneously, more economically, and with a reduced number of incorrect segmentations; this latter is achieved by specifying the respective environments of potential elements;

- simple and efficient treatment of exceptions, for instance the pronunciation of foreign words; this and the preceding result in a reduced transcription error rate and in simplified and more transparent grapheme-to-phoneme conversion rules;

- correct placement of word-internal boundaries, labelling of the constituents and the lexically stored information concerning native va. foreign status favour accurate word stress assignment;

- the lexicon-based approach prepares the ground for word classification and extraction of cortain syntactic constrainta, providing the input for an elementary sentence parger.

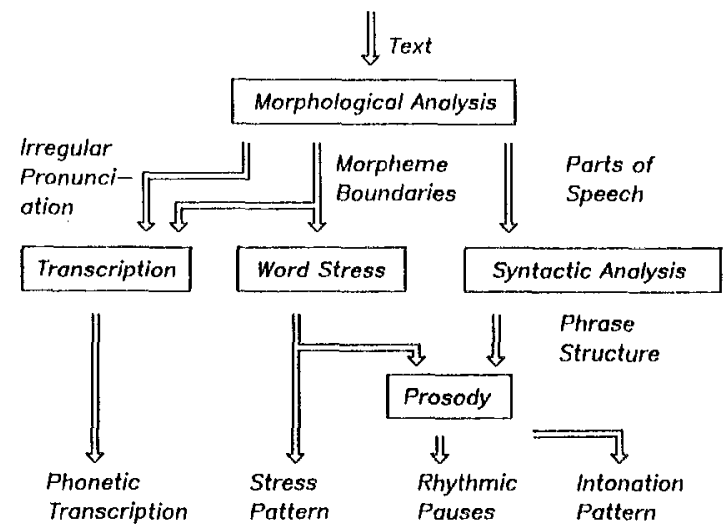

Fig. 1: The role of the morphological component within GRAPHON 


\section{SKETCH OF' THE MORPHOLOGICAL COMPONENT}

\subsection{Lexical lnventory}

Morphological analysis in our syatem relies on a aingle lexicon rather than on separate lists of, say, prefixes, stens, junctures etc. The entries in this lexicon are morphs and not morphemes in that stem variation, i.e. processes such as umlaut (e.g. Apfel Apfol "apple"), ablaut (lauf - lief "run") and e-deletion (trocken - trockn- "dry") are not covered by rule but by storage of allomorphs. As we are not concerned with generation, this appears to be the most practical method. Forms that are in some way irregular are then naturally provided with individual entries, for oxample anomalous verb forms (sein - bin - war - wär - ... "be") or forms of the definite article (der, die, das, dem,...). Wo have chosen to set up the most basic forms wherever possible, e.g. NAMas opposed to NAME (nominative singular), which permite an economical treatment of derivation and inflection. As a matter of fact, the overriding principle governing the decision what exactly should constitute an entry is a pragmatic one: for example, rather than taking sides on linguistic, historical, or psychological grounds in such controvergial cases as antwort- va. ant + wort- ("answer"), himbeer- v8. him + beer ("raspberry"), or verliek vs, ver + lier("lose"), we choose the solution favouring the ideal functioning of the system as a whole.

\subsubsection{Structure of a Dictionary Entry}

A dictionary ontry consists of the lemma, i.e. graphemic representation of the morph, on the one hand and an information-tree, gerving to characterize its phonological, morphological and syntactic value on the other.

A number of practical conventions has been set up for the form of the lemma: a given morph is represented by maximum of ten lower-case letters; the diacritic sign " (umlaut) is made use of (cf. other systems which decompose the vowels in question as $\langle a \theta\rangle,\langle 0 \theta\rangle,\langle u \theta\rangle)$; likewise, the sign $\langle B\rangle$ is not replaced by 〈ss〉 either in the input text or in the lexicon. An orthographic rule of German states that 〈s8〉 becomes (B) before a consonant or a word-boundary, so that. the latter sig'n's usual function as an indicator of vowel length is neutralized in these positions (compare Flügse "rivers" vs. FüßBe "feet" with FluB (/u/) va. FuB (/u:/)); this "defect" (cf. [10], p.108) can be got round by maintaining the opposition between $\langle B 8\rangle$ and $\langle B\rangle$ in the lemma.

The information-tree contains classificatory data pertaining to the morph itself and to those it may immediately select; they concern morphological stalus ( lexical stem - particle - derivational morph inflectional morph - juncture -...), native or foreign status, and combinatorial restrictions. In addition, the lexicon allows the introduction of information for the assignment to parts of speech and, wherever necessary, indicationg as to exceptional pronunciation or gtress pattern.

\subsubsection{Extent of the Lexickl Inventory}

At present the lexical inventory comprises some 2000 entries, the choice of which was based on Ortmann [11], itself compiled from four frequency lists. As for the contents of the entries, we relied on Augat [12], Mater [13], and Wahrig [14]. For the ongoing testing, revision, and supplementing of this primary list we depend on the frequency list in Meier [15] as well as on sample texts from various random sources. Inasmuch as affixes, particles, and junctures (at least native ones) constitute closed classes, they should be represented exhaustively in the inventory. This ia unfortunately not the case as soon as one turns to foreign elementa, to whose number are always being added new candidatea. Moreover, it is very difficult if not impossible to establish general principles according to which foreign suffixes in particular may be isolated and the dividing line found between stem and suffix.

proper nouns are repreaented only to a very limited extent; their range should be adapted to the requirements of the task at hand. In fact, the compilation of the inventory has been carried out with the aims of expandability and maximurn plexibility.

It is of course not to be expected that the lexicon would ever cover the entire vocabulary of a native speaker, nor is that our intention; consequently, we foresee a "joker morph" which can stand for any stem that may happen to occur. This is made possible 
by the generalization that a German stem conforms to a number of structural principles: for example, every stem must contain a vowel and the variety of consonant clusters in initial, medial, and final position is restricted (cf. [8]). An even more general canonical description can be exploited in the case of foreign elements. Such a device has not yet been implemented.

For the time being, 64 kbyte have been reserved to accomodate the lexical inventory. Note that all lexical data as described above are coded so as to achieve maximum storage efficiency.

\subsection{Word Parser}

The segmentation of a given (complex) word is carried out automatically in a series of steps; the process is bound from the very first of these to the dictionary, as stated above. Just as the human speaker seeks familiar units in his identification of a word, the automatic analysis considers for further attention only those segments which correspond to forms available in the lexicon, such that the segments are contiguous and no letters are left unaccounted for. Thus a segmentation such as mein $+u n+g$ for Meinung ("opinion") could not be produced in the first place, as +g't has no representation in the lexicon. The number of potential analyses is further reduced by the fact that no boundaries are searched for in a word corresponding identically to a single unit in the lexicon, for example der would not be analyzed as $d+$ or or $d+e+r$. For reasons of run-time efficiency, a strategy is used which "preferg" the longest segments, starting from the beginning of a given wordi thus deck + on ("cover") would be the first segmentation proposed before $d+e c k+e n$. The usefulness of this principle can be seen from an example like Eintritt ("entrance"), where the order of segmentations would be: ein + tritt, ein $+t+$ ritt, ei $+n+$ tritt, oi $+n+t+$ ritt, $\theta+$ in + tritt, $\quad \theta+i n+t+$ ritt, $\quad \theta+i+n+$ tritt, $e+i+n+t+$ ritt. The first decision proposed by the parser can be proved to be the correct one in the overwhelming majority of cases, which allows us to delay requiring a eecond proposal until the first has been rejected on structural grounds in the following step of the analysis procedure.
In this second step the proposed segmentations are examined as to their conformity to the principles of German morphological structure. The following structural formula describes every German word, whether of native or forelgn origin:

$$
\left[P_{0}^{2}+S+D_{0}^{5}+J\right]_{0}^{\infty} \# P_{0}^{3}+S+D_{0}^{5}+I_{0}^{1}
$$

whereby:

$x_{a}^{b}$...there may be between $a$ and $b$ segments of this type in a given structure

+ \# represent morphological boundaries of different strengths (differentiation relevant for the context of certain phonological rules)

P... Particle (in general equivalent to inseparab].e prefixes, e.g. +ent+, tprät)

s.... Stem

D... derivational morph, always a suffix (e.g. $\left.+i g^{t},+u n g t-\right)$

I... inflectional morph, always a suffix (e.g. +ent, +emt)

J... juncture morph (e.g. +est in Bundesbahn "national rail.way")

The segmentation is assigned atructural description by matching the combinatorial features of each unit with the morph status information of its neighbour as given in the respective lexicon entries. A morph may be specified according to the following propertios and in turn select certain values for these properties in its neighbour:

- native or foreign status,

- lexical functionality (this property is manifested by the capacity to receive inflection),

- morphological status (as in the above structure definition with additional detailed classification), and

- lexical class, i.e. part of speech as roflected in the inflectional ending.

Specification of these properties is optional; however, the more information provided, the more restrictions with respect to the general structure formula are achieved, so that the number of potential labellings is reduced and the labellings themselves bear more information. Thus, it is possible to provide at least a partial treatment for words whose stems are not represented in the 2000 entry lexicon.

Should no match be obtained in this step, the process is repeated with a new segmentation until compatible sets of features are found. 


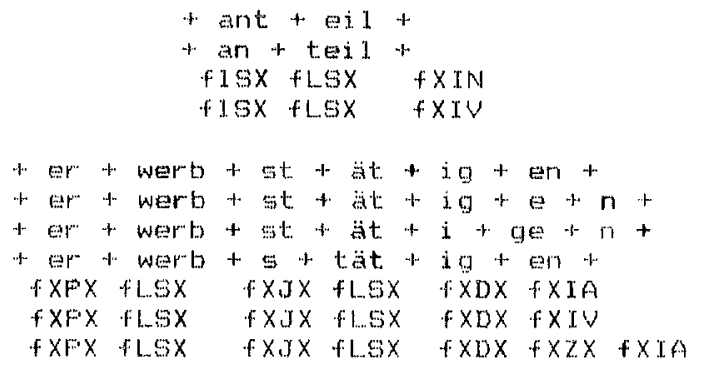

Fig. 2: Sample segmentations and structural specifications

$$
\begin{aligned}
& \text { f/F...native/foreig } \mathrm{r} \\
& \text { 1/L...lexical/non-lexical } \\
& X \text {... unspecified } \\
& \text { P ... particle } \\
& \text { S... stem } \\
& J \text {... junction } \\
& \text { D ... derivational morph } \\
& \text { I ... inflectional morph } \\
& \text { 2 ... participle mor ph } \\
& \mathrm{N} \text {... noun } \\
& \text { A ... adjective } \\
& \text { V ... verb }
\end{aligned}
$$

Fig. 2 pregenta examples of the resulting segmentations and labellings. We see that the firat segmentation of Anteil ("portion") is rejected, as in this case the stem would be preceded by a suffix (tantt being a longer gegment than tant, it has received "priority" up to this point). In the second segmentation, tant is correctly recognized as a nor-lexical stem, upon which a lexical stem may follow. It is not possible to specify the lexical class selected by tant, as it combines with all parts of spoech; and as +teilt can function as a noun or a verb stem, there result two potential labellings. The ambiguity cannot be resolved at this stage.

The following example is gomewhat more complicated. Crucial here is the boundary between the two stems of the compound Erwerbstätigen ("employees"): the phonological consequences of an error (/ft/ instead of /st/) are quite serious. After the correct aegmentation has finally been found, three possible interpretations are proposed. Note that tent can serve as a participle morph $(Z)$, so that the word would syntactically function as an adjective.

The third step consigts of additional checks and finer specifications in order to isolate the correct structure and part-of-speech assignment for the whole word. For instance, if a suffix has been identified as a possible past participle morph, this could be verified by searching for a corresponding prefix (cf. teil $+t$ "ghares" va. ge $+t e i l+t$ "ghared"). Another check could exploit certain reatrictions on the sequence of lexical and non-lexical atems in a complex word. Such tests have not as yet been implemented.

The lexical class of a German word is, generally apeaking, determined by ita last element, so that the classification algorithm makes use of the results of the matching process at the end of the word. Some derivational morphs, e.g. +ungt, +keitt, tischt, permit unambiguous classification. Unfortunately the same cannot be aaid of inflectional endings in particular and many other elements as well, taken alone. By ex-

\begin{tabular}{|c|c|c|}
\hline$(F)$ & tol $\mathrm{E}$ & [di:] \\
\hline$(A, V)$ & $+y^{m}$ ict $t+i g+$ & {$[r \mathrm{~s}, \mathrm{t}$ iga $]$} \\
\hline (N) & +2 est + legtung + & {$[$ tse $1 \mathrm{e}: \mathrm{g} \cup \mathrm{J}$} \\
\hline$(H)$ & Hont & [von] \\
\hline$(N, A)$ & + wort $t+e r n+$ & [vort tyo] \\
\hline (V) & $+i \operatorname{sit} t$ & {$[$ [ $匚$ it $]$} \\
\hline$(A, V)$ & twictitwigk & {$[\vee x \leq t \leq]$} \\
\hline (F) & $+f u i r+$ & {$[$ fys $]$} \\
\hline$\left(F^{\prime}\right)$ & $+d i$ & $\operatorname{Codj}: \ddot{y}$ \\
\hline$(N)$ & the+stimmwngt & [tos trimut] \\
\hline$(A, N, V, A)$ & $+\mathrm{i} n r^{\prime \prime}+\mathrm{er}^{\prime}+$ & {$\left[i: r^{2}\right]$} \\
\hline$(N, V)$ & taustsprachtet & 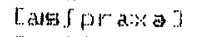 \\
\hline$(F)$ & turndt & [unt] \\
\hline (N) & wbetton+ung+ & {$\left[\mathrm{bata:n} \mathrm{rr}_{\mathrm{j}}\right]$} \\
\hline$\langle F\rangle$ & rundt & [unt] \\
\hline (Fi) & $+f \ddot{i r}+$ & 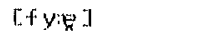 \\
\hline$\langle F\rangle$ & $+d i e+$ & [di: ] \\
\hline (IV) & $+e r+z e L g+149 g+$ & {$[E:$ tsolgur] } \\
\hline$\langle F i\rangle$ & Hdert & [deg] \\
\hline$\langle\mathrm{N}\rangle$ & wsatz thelodw & [zatsme ] odi: ] \\
\hline
\end{tabular}
ploiting the combinatorial information, however, many ambiguities are eliminated; moreover, capitalization can be treated as a signal for the lexical class noun.

Each text unit is now provided with a structural specification such that the phonological, syntactic and prosodic componente may operate on it. Fig. 3 shows segmentations and lexical class assignment for a sample sentence; based on these, the phonological component already in place determines the correct pronunciation and generates the r.P.A. transcription, also given in fig. 3 .

F'ig. 3: Sample segmentations, lexical class assignment and rosulting I.P.A. transcription

N...noun; A...adjective; V...verb; R...other 


\section{CONCLUSION}

Although extensive testa on large corpora have not as yet been carried out, experiments with our current system permit evaluation of following aspects of the morphological analysis component in GRAPHON:

- The development of the phonological component has shown that the setting up of a catalogue of pronunciation rules became gimpler and more Bystematic, and at the same time, the rate of transcription errors could be greatly reduced.

- A relatively limited number of lexical entries is capable of handling a considerable quantity of running text. The morphological information stored in each entry has proved to be relevant and in general sufficient for correct gegmentation. However, in order to increase accuracy in determining lexical class, as required by the syntactic analysis, it would be advantageous to expand the number of categories represented in the lexicon entries. As it was not clear before the present testg exactly which additional clasgification would be useful, we chose to start from a minimum and provide for easy future expansion. For example, the experiments confirm our assumption that it would be desirable to specify the potential junctures for a given stem and to differentiate several inflectional paradigms within a lexical class, in particular strong and weak verbs. These data would have resolved the ambiguities encountered for the sample words in Fig. 2.

- As the aims of our system do not include any attempt to incorporate semantice and as moreover there is no feedback from the ayntactic component planned, a unique structural specification cannot be expected in the case of ambiguities requiring reference to these structural levels. Since such ambiguities do not necessarily lead to incorrect grammatical apecification and only rarely to incorrect pronunciation, this is only a relative limitation.

Correctness of the phonemic tranecription certainly accounts for a great part of the quality and acceptability of a text-to-speech system. Nevertheless it is often claimed (e.g. [6]) that synthetic speech should be evaluated along further dimensions, such as intel- ligibility, listening comprehengion and naturalness. One goal of the approach presented here is to lay the ground for the incorporation of rules for the assignment and realization of stress and intonation patterna not only on the word but also on the sentence level. Thus the basic phonetic transcription will be extended and modified so as to give a representation closer to natural speech.

\section{REFERENCES}

[1] Kommenda, M.: "GRAPHON - ein System zur Sprachsynthese bei Texteingabe".

In: H. Trost and J. Retti (Eds.), Osterreichische Artificial Intelligence-Tagung. Springer, Berlin, 1985.

[2] Allen, J.: "Synthesis of Speech from Unrestricted Text".

Proc. IEEE, vol. 64 (1976), pp. 433-442.

[3] Wolf, H.E.: "Sprachvollsynthese mit automatischer Transkription".

Der Fernmelde-Ingenieur, vol. 38 / no. 10 (1984), pp. 1-42.

[4] Mangold, H.; Stall, D.S.: "Principles of Text-Controlled Speech Synthesis with Special Application to German".

In: L. Bolc (Ed.),

Speech Communication with Computers. Carl Hanger, München, 1978, pp. 139-181.

[5] DUDEN Aussprachewörterbuch. Bibl. Inst., Mannheim, 1974.

[6] Rühl, H.-W.: Sprachsynthese nach Regeln für unbeschränkten deutschen Text. Dissertation Ruhr-Universität Bochum, Germany, 1984

[7] Müller, B.S.: "Regelgesteuerte Umsetzung von deutschen Texten in gesprochene Sprache für das Sprachausgabegerët VOTRAX". In: B.S. Müller (Ed.), Germanistische Linguistik, vol. 79-80 (1985), pp.83-112.

[8] Kästner, W.: Automatische Phonemigierung orthographischer Texte im Deutschen. Helmut Buske, Hamburg, 1972.

[9] Menzel, W.: " A Grapheme-to-Phoneme Transformation for German". Comp. \& AI, vol.3, 1984, pp. 223-234.

[10] Philipp, M.: Phonologie des Deutschen. Kohlhammer, Stuttgart, 1974.

[11] Ortmann, W.: Wortbildung und Morphemstruktur eines deutachen Gebrauchswortschatzes. Goethe-Institut, München, 1983.

[12] Auggt, G.: Lexikon zur Wortbildung. Forschungaberichte des IdS, vol. 24.1-4. Gunter Narr, Tübingen, 1975.

[13] Mater, E.: Rückläufige日 Wörterbuch der deutachen Gegenwartsaprache. Bibliographisches Institut Leipzig, 1983.

[14] Wahrig, G.: Deutsches Wörterbuch. Gütersloh, 1983.

[15] Meier, H.: Deutsche Sprachstatistik. Georg Olma, Hildesheim, 1978. 